\title{
Classroom Enjoyment and Anxiety among Saudi Undergraduate EFL Students: Does Gender Matter?
}

Elias Bensalem

Department of Languages and Translation Northern Border University, Saudi Arabia elias.bensalem@nbu.edu.sa

\begin{abstract}
The current study was motivated by recent interest in the effect of positive and negative emotions in the context of foreign language learning resulting from the rise of the positive psychology movement (Dewaele \& MacIntyre, 2016; MacIntyre \& Mercer, 2014). It examines the construct of foreign language enjoyment (FLE) and its relationship with foreign language classroom anxiety (FLCA) among a group of 487 English as a foreign language (EFL) students (340 females, 147 males) enrolled in public universities in Saudi Arabia. A measure of FLE based on Likert scale ratings of ten items (Dewaele \& MacIntyre, 2014), and a measure of FLCA based on eight items extracted from the FLCAS (Horwitz et al., 1986) were used. Male and female students had the same levels of FLE and FLCA. Correlation analysis showed that the relationship between students' FLE and FLCA was significantly negative. Qualitative analysis of the participants' learning experiences revealed the causes of FLCA and FLE among Saudi EFL learners.
\end{abstract}

Keywords: Classroom language anxiety, EFL learners, gender, foreign language enjoyment, positive psychology.

\section{Resumen}

El estudio actual está motivado por el reciente interés sobre el efecto de las emociones positivas y negativas en la adquisición de un idioma extranjero, como resultado del incremento del movimiento psicológico positivo (Dewaele $\&$ Macintyre, 2016; MacIntyre \& Mercer, 2014). Examina el constructo del disfrute de la lengua extranjera (FEL) y su relación con la ansiedad en la clase de lengua extranjera (FLCA) entre un grupo de 487 estudiantes de inglés como lengua extranjera (EFL) (340 
mujeres, 147 hombres) matriculados en universidades públicas en Arabia Saudí. Se utilizó una medida de FLE, basada en los rangos de la escala Likert de diez ítems (Dewaele \& MacIntyre, 2014) y una medida de FLCA basada en 8 ítems extraídos de los FLCA (Horwitz et al., 1986). Los hombres y las mujeres mostraron los mismos niveles de FLE y FLCA. El análisis de correlación mostró que la relación entre la FLE de los estudiantes y la FLCA fue significativamente negativa. El análisis cualitativo de participantes en la experiencia de aprendizaje reveló las causa de FLCA y de FLE entre los aprendices de EFL.

Palabras clave: Ansiedad en aula, aprendices de inglés como lengua extranjera, género, disfrute del idioma extranjero, psicología positiva.

\section{Introduction}

The role of emotion in the field of second language acquisition (SLA) used to be a neglected area of research. Swain (2013) argues that "emotions are the elephants in the room-poorly studied, poorly understood, seen as inferior to rational thought" ( $\mathrm{p}$. 11). Dewaele (2005) claims that only a small number of studies examined the potential impact of emotions on language learning. However, until recently, the literature has focused mostly on negative emotions such as anxiety, while positive emotions have not received enough attention (Bown \& White, 2010; Fredrickson, 2001). The bulk of studies on negative emotions focused on the construct of foreign language anxiety (e.g., Dewaele et al., 2019a; Jin \& Dewaele, 2018; Horwitz, 2001; MacIntyre, 2017). With the introduction of the concept of Positive Psychology into the field of SLA by MacIntyre and Gregersen (2012), many scholars have started to examine both negative and positive emotions as essential elements in the process of language acquisition (e.g., De Smet et al., 2018; Dewaele \& MacIntyre, 2014; Dewaele \& MacIntyre, 2016; Dewaele \& Dewaele, 2017; Elahi Shirvan \& Taherian, 2018). Furthermore, many studies have explored the potential role played by different variables in learners' experience of FLE and FLCA such as age (e.g., Dewaele et al., 2018; Dewaele \& MacIntyre, 2014; Dewaele \& MacIntyre, 2019), the number of languages studied (e.g., Dewaele et al., 2018; Dewaele \& MacIntyre, 2014; Dewaele \& MacIntyre, 2019), and teacher friendliness (e.g., Dewaele \& MacIntyre, 2019; Dewaele et al., 2019a; Dewaele et al., 2019b). The role of gender was also another variable explored by a few studies (Dewaele \& MacIntyre, 2014; Dewaele et al., 2019a; Jiang \& Dewaele, 2019) primarily in an international context, in China and the United Kingdom. Gender differences merit exhaustive examination (Jiang \& Dewaele, 2019).

Based on the above, it would be useful to examine whether female learners who study EFL in a different educational and linguistic setting experience more enjoyment 
than their male counterparts. The understanding is that sociocultural factors, especially the status of women in society, determine the role of gender in foreign language (FL) learners' experience of FLCA (Bensalem, 2018; Park \& French, 2013; Song, 2018). Denies and Janssen (2016) argued that gender differences may also vary from one country to another.

The present study seeks to explore this line of research through learners' FLE and FLCA in the Saudi EFL tertiary level context. More specifically, this study sets out to explore whether gender affects FLE and FLCA of EFL learners. In addition to investigating the impact of the gender variable on anxiety and enjoyment, the study seeks to identify and detect the sources of FLE and FLCA among male and female students in the underexplored Saudi educational EFL setting.

\section{Literature review}

The inclusion of positive emotions in SLA is based on the premise that positive emotions may help facilitate the language learning process (MacIntyre \& Gregersen, 2012). It is not sufficient to stimulate students by alleviating negative emotions (Dewaele \& Alfawzan, 2018). There is a need to recognize enjoyment as a powerful motivator in SLA (Pavelescu \& Petrin, 2018; Piniel \& Albert, 2018). For Boudreau et al. (2018), foreign language enjoyment is a "complex and stable emotion" that is entirely separate from the "more superficial experience of pleasure" (p.153).

\subsection{Studies on foreign language enjoyment}

A large-scale study on FLE was conducted by Dewaele \& MacIntyre (2014) involving $1.740 \mathrm{FL}$ learners from childhood to adulthood and from all corners of the globe. The authors developed a 21-item FLE scale to measure positive emotions towards the learning experience, peers, and teacher. Eight additional items extracted from Foreign Language Classroom Anxiety Scale (FLACS; Horwitz et al., 1986) were added to measure participants' FLCA. Statistical analysis showed that there was a negative correlation between FLE and FLCA. The authors argued that even though the two constructs are interrelated, they constitute, nevertheless, separate dimensions. Another interesting finding is that students who exhibited significantly higher levels of FLE and lower levels of FLCA had a higher level of multilingualism and a more advanced level of proficiency; they felt they outperformed their peers in the language class at the college level and beyond.

The same dataset was used by Dewaele \& MacIntyre (2016) to examine the underlying dimensions of FLE. Results of factor analysis generated three dimensions: 
FLCA, social FLE, and private FLE. Together, these accounted for $45 \%$ of the variance. The authors found that the social FLE dimension was independent of the private FLE dimension.

In a pseudo-longitudinal study, Dewaele \& Dewaele (2017) examined the development of FLE and FLCA among 189 foreign language students from two topperforming schools in the UK. Participants were divided into three age groups: 12-13 year olds (age group 1), 14-15 year olds (age group 2), and 16-18 year olds (age group 3). A Pearson correlation analysis revealed a significant negative correlation between FLE and FLCA only in age group 2; participants who had higher levels of FLE experienced lower levels of FLCA. Results showed slight variation in FLCA and a small increase in FLE. A repeated measures analysis of variance revealed little variation in FLCA and a slight increase in FLE among the participants. Furthermore, the data showed that the causes of positive and negative emotions are not static and tend to change over time.

Using the same data set of the previous study, Dewaele et al. (2018) investigated the effect of learner-internal and learner-external variables on levels of FLCA and FLE among 189 secondary school students who were mostly taking French, German, or Spanish courses. Results showed that participants had significantly higher levels of FLE than FLCA. Furthermore, a weak negative relationship between FLE and FLCA was reported, which corroborates the results reported in Dewaele and MacIntyre (2014). Finally, gender played a role in participants' experience of FLE and FLCA since female students had higher levels of FLE and FLCA than male students.

In the Canadian context, Boudreau et al. (2018) examined the dynamic relationship between FLE and FLCA in a second-by-second analysis of a group of ten college-level English-speaking students learning French as an L2. Participants had to complete oral tasks while being video recorded. First, they were instructed to describe a photograph of something they thought was enjoyable for a few minutes. Then, they were given five oral interview style questions. Idiodynamic software was used to rate students' anxiety and enjoyment while they watched their recorded tasks. The computer software generated a graph of the participant's ratings. The researcher and the participant examined the graph and discussed spikes and dips in ratings. The researchers examined the correlation between FLE and FLCA for each participant; similarly, correlation was examined for the photo description and the oral interview. This approach was used to measure the fluctuating relationships between FLE and FLCA. Data analysis showed a complex correlation between FLE and FLAC. In certain situations, FLE and FLCA moved closer to each other, while in others, they were further apart. In some situations, there was no relationship between the two, and both acted in separate ways. 
The role of the target language in influencing learners' FLE and FLCA has also been a topic of interest. De Smet et al. (2018) undertook a study that compared anxiety and enjoyment among students learning two different target languages (English and Dutch). A group of 896 pupils from elementary and secondary education schools in French-speaking Belgium, located in two educational contexts, namely content and language integrated learning (CLIL) and non-language integrated learning (nonCLIL), participated in the study. Results of data analysis revealed that CLIL pupils exhibited lower levels of anxiety than non-CLIL pupils did. Furthermore, Dutch learners experienced more anxiety and less enjoyment than English learners. These findings suggest that emotional engagement may be a function of the target language.

Attempting to examine potential difference between FLE and FLCA among learners from different linguistic settings, Jiang \& Dewaele (2019) compared FLE and FLCA of English as a foreign language (EFL) students in China to learners in other countries. The authors found that participants reported significantly higher levels of enjoyment than anxiety in their English classes. This finding is consistent with previous research (Dewaele et al., 2017; Dewaele \& Dewaele, 2017; Dewaele \& MacIntyre, 2014; Khajavy et al., 2018). The mean of FLE was higher than the mean in the Dewaele \& MacIntyre's (2014) sample, which included learners from all over the world. The mean of FLCA, however, was much higher than the mean of the international sample. The researchers attributed Chinese EFL learners' tendency to experience higher levels of anxiety than their overseas peers to the educational system in China, which does not provide ample opportunities for EFL learners to practice English (see Shi, 2008).

Finally, studying FLE and FLCA in Saudi Arabia has barely started to draw the interest of researchers, and so far, only one study has been carried out by Dewaele $\&$ Alfawzan (2018). The authors examined the effect of FLE and FLCA on English language performance among a group of 152 Saudi learners and users of English. The majority of participants had completed their undergraduate education, while the remaining participants were undergraduate English students. The authors reported that participants' higher levels of FLE were correlated with significantly higher English proficiency scores. Conversely, participants' higher levels of FLCA were linked to lower English proficiency scores. The qualitative data suggested interactions between participants' experience of FLE and FLCA in their English classes. The participants' experiences of FLE and FLCA were shaped by their perception of the teacher and teachers' pedagogical practices in the classroom. These findings are consistent with the study outcomes reported by Mierzwa (2019a). Participants in this study cited teacher-related variables such as teacher attitude, level of support provided to students, teaching strategies, and classroom activities as the primary sources of FLE. 


\subsection{Self-perceived language proficiency and foreign language enjoyment and foreign language classroom anxiety}

Very few studies explored the relationships between FLE, FLCA, and learners' selfperceived language proficiency. Dewaele \& MacIntyre reported self-perceived foreign proficiency as one of the significant predictors of both FLE and FLCA. Similarly, Li et al. (2018) found that for EFL Chinese students at different levels, both FLCA and FLE are significant predictors of their self-perceived proficiency in English.

\subsection{Gender differences in foreign language enjoyment and foreign language classroom anxiety}

Studies examining the role of gender in FL learners' experience of FLE yielded inconsistent results. Dewaele et al. (2016) conducted a study on the same dataset used by Dewaele \& MacIntyre (2014) to investigate potential gender differences at item level. The data revealed that female students $(n=1,287)$ experienced more enjoyment in foreign language lessons, actively agreed they had acquired interesting knowledge, and were more appreciative of their foreign language prowess than their male counterparts $(n=449)$. The female students also reported more excitement in the foreign language class than their male peers. They enjoyed being able to express themselves and learning something new. Unlike their male counterparts, they felt anxious about making mistakes and were unsure of themselves at times. In a more recent study involving 750 FL learners from around the world, Dewaele \& MacIntyre (2019) confirmed females' tendency to experience higher levels of FLCA but did not find any evidence supporting the view that female learners report more enjoyment than male learners. A different role for gender was reported by Dewaele et al. (2019b). In their study which involved 592 learners of Turkish as a foreign language in Kazakhstan they found that no gender differences existed for FLE, while male participants experienced higher levels of FLCA than female participants (Dewaele et al., 2019b). The absence of the role of gender for FLE was also reported by Mierzwa (2019b). In her study, students enrolled in English Philology classes exhibited the same levels of FLE regardless of their gender or proficiency level.

In their seminal article, De Smet et al. (2018) found that different populations of learners studying two different foreign languages, namely English and Dutch, experienced varying levels of FLCA and FLE. They attributed this difference to how each foreign language is perceived, to the level at which it is studied, and the manner in which instruction is delivered: content and language integrated learning (CLIL) on the one hand, and non-CLIL on the other. 


\section{The present study}

So far, only a limited number of studies have examined the role of gender in FL learners' experience of FLE. No single study has been conducted yet in male-dominated societies, such as the ones located in the Arabian Gulf region. Previous research has shown that learners' experience of FLCA is determined by sociocultural factors. What remains to be further explored is whether these same factors would affect learners' FLE. So far, only one study on FLE was conducted with Arab EFL students. This study involved participants who had already completed their undergraduate education. However, it did not control for the fact that over half of the participants had travelled outside Saudi Arabia, where they had studied or used English. Therefore, its outcomes cannot be generalized. Thus, the puzzle of FLE and its relationship with FLCA among Saudi students remains incomplete.

There are three motivations for the present research. The first to enrich the emerging literature on the newfound interest in the effect of positive and negative emotions on foreign language learning in terms what De Smet et al. (2018) call emotional engagement, FLCA, and FLE. The second motivation is to investigate the effect of context on how learners perceive and experience these feelings. The context under scrutiny here is Saudi Arabia, where an empirical investigation is called for to unpack the complex relationship between FLE, FLCA and self-perceived FL proficiency in English. All the participants were Arabic first language users studying EFL and with no experience studying or staying abroad. In order to fine-tune the outcomes of this study, the gender variable is added in hopes of finding out whether Saudi female learners who study EFL experience more enjoyment than their male counterparts. This third motivation is driven by the prevailing understanding that gender as a sociocultural construct impacts how FL learners in different countries experience FLE and FLCA and may even attain different FL proficiency levels. The following research questions will guide the present study:

1. What are the levels of FLE and FLCA of Saudi EFL learners?

2. Is there a relationship between Saudi EFL learners' levels of FLE and FLCA?

3. Are there any differences between male and female Saudi learners' levels of FLE and FLCA?

4. What is the effect of self-perceived proficiency in English and year of study on FLE and FLCA of Saudi EFL learners?

5. What are Saudi learners' views on enjoyable and anxious experiences in the EFL class? 


\section{Method}

\subsection{Participants}

A total of 487 EFL Saudi students (340 females, 147 males) participated in the study. They are all native speakers of Arabic. Their ages ranged from 18 to $33(\mathrm{M}=$ $21, S D=2.45$ ). About $33.7 \%$ are freshman, $24.2 \%$ are sophomore, $18.1 \%$ are junior, and $24 \%$ are senior (see Table 1). All students were required to enroll in a preparatory English program prior to enrollment at the university. It is an intensive five-course (half-semester) program which aims at developing the English proficiency required in a university. Students who finish the program should have at least an intermediate level of English. None of the participants had study abroad experience. Since permission to measure students' levels of proficiency through a proficiency test was not granted, the researcher decided to use a self-rated proficiency measure as an alternative method. Participants were instructed to rate their proficiency in English on a scale from 1 to 10 for listening, speaking, reading and writing are reported. The same scale was used in previous studies (e.g., Santos et al., 2017; Thompson \& Lee, 2013). Participants' English self-perceived proficiency levels are reported in Table 2.

Table 1: Participants' background information

\begin{tabular}{llll}
\hline Variable & Category & Frequency & Percentage \\
\hline Gender & Female & 340 & $69.8 \%$ \\
& Male & 147 & $30.2 \%$ \\
Year of study & Freshman & 164 & $33.7 \%$ \\
& Sophomore & 118 & $24.2 \%$ \\
& Junior & 88 & $18.1 \%$ \\
& Senior & 117 & $24 \%$ \\
\hline
\end{tabular}

Table 2: English self-perceived proficiency levels

\begin{tabular}{lll}
\hline & $M$ & $S D$ \\
\hline Speaking $(\max =10)$ & 6.41 & 1.96 \\
Listening $(\max =10)$ & 7.29 & 2.43 \\
Reading $(\max =10)$ & 7.28 & 2.11 \\
Writing $(\max =10)$ & 6.43 & 2.28 \\
\hline
\end{tabular}




\subsection{Instruments}

Data were collected through an Arabic version of Dewaele \& MacIntyre's (2014) self-report questionnaire measuring students' anxiety and enjoyment in the classroom, along with background information. The questionnaire was used in recent studies (Jiang \& Dewaele, 2019; Li et al., 2018). The first section of the survey included questions that elicited participants' sociobiographical information related to their age, gender, and year of study. The second section included 10 items from Dewaele $\&$ Dewaele (2017) that were extracted from the original 21-item FLE questionnaire (Dewaele \& MacIntyre, 2014). The items, which were all positively phrased, were based on five-point Likert scales ( $1=$ strongly disagree, $2=$ disagree, $3=$ neutral, $4=$ agree, 5 = strongly agree). In terms of internal consistency, the Cronbach's alpha for the FLE scale was. 703, suggesting acceptable internal consistency. The third section of the survey consisted of eight items extracted from the FLCAS (Horwitz et al., 1986) and used in Dewaele \& MacIntyre (2014). They were used to determine participants' anxiety levels and were based on five-point Likert scales ( $1=$ strongly agree, $2=$ agree, $3=$ neutral, $4=$ disagree, $5=$ strongly disagree). Six items were positively phrased. The two remaining items were reverse coded since they were negatively phrased. High scores indicate high levels of anxiety. The scale had a good internal reliability (Cronbach alpha $=.781$ ). The questionnaire ended with two open questions. Participants were asked to describe one memorable enjoyable learning experience of enjoyment and one memorable anxious learning experience in the EFL class.

\subsection{Procedure}

After obtaining the Human Research Ethics Committee's approval, a number of teaching staff from target institutions helped recruit participants for the study. The participants were informed of the purpose of the research and were assured that the collected data would be kept confidential. All survey items were formulated in Arabic, the native language of students in order to ensure that participants fully understood the survey items. An Arabic version would increase the participation rate as students were more comfortable with Arabic. Participants were provided with a link to a Google form containing the survey, which was completed anonymously. The survey took about 15 minutes to complete. Data collected from Google form were coded and analyzed using the Statistical Package for Social Sciences (SPSS).

\subsection{Data analysis}

A data-validation variant of a convergent parallel mixed-methods design (Creswell $\&$ Plano Clark, 2011) was adopted. The quantitative data (closed questions) aims 
at measuring participants' levels of FLE and FLCA among males and females and identifying the link between FLE and FLCA. The qualitative data (open questions) is used to analyze participants' enjoyable and anxious experiences. Creswell \& Plano Clark (2011) argue that mixed method research design enables a greater degree of understanding than if a single approach was adopted. They argue that qualitative items "provide the researcher with emergent themes and interesting quotes that can be used to validate and embellish the quantitative survey findings" (p.81).

The data analysis was performed in two stages. In the first stage, descriptive statistics (i.e., means and standard deviations) were used to summarize participants' responses. As Kolmogorov-Smirnov test revealed that the distribution was not normal, $D(487)=0.084, p<.001$, a Mann-Whitney $U$ test was carried out to examine whether there were differences in FLE and FLCA between male and female participants. Furthermore, Spearman Rho correlation analysis was performed to examine any statistically significant correlation between FLE and FLCA. Furthermore, Linear regression analysis was used to assess the effect of the learners' self-perceived proficiency and year of study and determine their relative contribution to the prediction of FLE and FLCA.

In the second stage, content analysis was used to analyze participants' enjoyable and anxious experiences in the EFL class following Dewaele \& MacIntyre (2014). The data was coded into main themes. Many respondents chose to respond to the open-ended questions in Arabic or sometimes in a mix of Arabic and English, which made it difficult to use Nvivo software. Therefore, the data was coded manually. Data extracts were selected from the open questions guided by the principle that they are representative of a particular topic, concise, and interesting.

\section{Results}

The findings of the study will be presented in two sections. The first section will present quantitative findings related to levels of FLE and FLCA among male and female participants, and the relationship between FLE and FLCA. Furthermore, statistical results regarding the effect of self-perceived proficiency in English and year of study on the participants' FLE and FLCA will be presented. The second section will present the quantitative findings. It reports on participants' views on enjoyable and anxious experiences in the EFL class. 


\subsection{Quantitative findings}

\subsubsection{Levels of foreign language enjoyment and foreign language classroom anxiety and gender differences}

Average scores on the 5-point scale were calculated for FLE $(M=3.61, S D=0.59)$ and for FLCA $(M=3.70, S D=0.70)$. Whilst the levels of FLE are comparable to the values reported in previous studies ranging from 3.4 (Dewaele $\&$ Alfawazan, 2018) to 3.9 (Jiang \& Dewaele, 2019), the levels of FLCA are reported higher by recent studies with a range between 2.4 (Dewaele et al., 2017) and 3.1 (Jiang \& Dewaele, 2019). A Mann-Whitney $U$ test was conducted to determine whether there was a difference in learners' levels of FLE and FLCA. The results indicated no significant difference between levels of FLE among male and female learners, $z=-1.87, p \square .05$. Female learners had an average rank of 251.83, while male learners had an average rank of 225.90. Similarly, there was no significant difference between levels of FLCA amongst male and female learners, $z=-1.87, p \square .05$. Female learners had an average rank of 236.17, while male learners had an average rank of 262.10. In terms of FLE individual items, compared to their male peers, the female participants felt significantly more that they were worthy members of the English language class. Female learners had an average rank of 261.62, while male learners had an average rank of 203.24, $(U=$ 18998.5, p [ .001). Similarly, female students agreed more strongly that it is "cool" to know English $(U=22125.50, p=.037)$. Regarding individual FLCA items, the female participants felt significantly more anxious in the English class even if they felt they were well prepared $(U=21718.50, p=.018)$. Furthermore, the female participants reported that they started to panic when they had to speak without preparation in the English class $(U=21085.50, p=.005)$.

\subsubsection{Relationship between foreign language enjoyment and foreign language classroom anxiety}

Spearman Rho correlation analysis revealed a perfect negative significant correlation between FLE and FLCA (Rho $=.19, p<0.001, r 2=.036)$. In other words, participants who had higher levels of FLE tended to have lower levels of FLCA. The effect size for FLE (0.036) can be described as "small" (Cohen, 1992), which means that the FLE and FLCA are not strongly correlated. 


\subsubsection{Effect of self-perceived English proficiency and year of study on the participants' foreign language enjoyment and foreign language classroom anxiety}

In order to examine the simultaneous effect of self-perceived proficiency in English and year of study (freshmen, sophomore, junior, and senior) on the participants' FLE and FLCA, multiple regression analysis was conducted. Results show that the presented model is significant as there was a significant relationship between self-perceived proficiency in English and FLE as well as FLCA ( $p=.03 ; r 2=0.084 ; r=0.290)$. The $R$ value for the regression model indicates a small linear relationship between English self-perceived proficiency and FLE. The same linear relationship was found between self-perceived proficiency and FLCA. The $r 2$ was 0.28 , which English self-perceived proficiency explains $8 \%$ of the variance in participants' FLE and FLCA. According to Cohen's (1988) criteria for assessing the predictive power of independent variables, this indicates a small effect size. Year of study was not a predictor of FLE and FLCA.

\subsection{Qualitative findings}

This section reports on participants' views on enjoyable and anxious experiences in the EFL class. A close reading of the participants' responses to the open questions generated the following themes: classroom activities, instructor skills, personal success/ failure in the classroom, assessment, and other (see Table 3). The revealed sources of anxiety and enjoyment are applicable for both males and females.

Table 3: Main themes in the feedback of participants' enjoyable and anxious experiences in the EFL class

\begin{tabular}{lllll}
\hline \multirow{2}{*}{ Theme } & FLE & \multicolumn{3}{l}{ FLCA } \\
\cline { 2 - 5 } & Frequency & $\%$ & Frequency & $\%$ \\
\hline Classroom activities & 126 & 25.8 & 87 & 17.9 \\
Instructor skills & 143 & 29.5 & 119 & 24.4 \\
Personal success/failure & 73 & 14.9 & 81 & 16.7 \\
Assessment & 57 & 11.8 & 94 & 19.2 \\
Other & 88 & 18 & 106 & 21.8 \\
\hline
\end{tabular}




\subsubsection{Classroom activities}

Some classroom activities are enjoyable, while others can cause anxiety among students. Many participants mentioned group activities as a source of joy for them. Participant 13 explained how she enjoyed task based activities:

During one of my English classes the teacher set up a group activity which involved everyone in the classroom. Each group member was handed a piece of paper with a specific task to complete. Students' tasks were rated by their fellow group members. Ratings were in the form of the number of stars. By the end of the task, each group would share the number of stars generated by group members. I really enjoyed this activity (P13, female).

Male participants share their appreciation of group activities. Participant 8 reported the joy of working with his classmates:

I enjoy participating in group activities which involve discussions among group members with the instructor interacting with us (P8, Male).

Some classroom activities were also sources of anxiety for many participants. Speaking activities involving students standing and addressing their classmates were cited as the most anxiety triggering events in the classrooms as Participant 25 remembers:

One day the instructor asked me to stand up and share my answer with the rest of classmates. I was not prepared so I became nervous and struggled to deliver. All students laughed and some even made fun of me. It was very embarrassing (P25, female).

Male students experienced similar anxious situations related to speaking. Participant 53 recalls:

The English teacher brought me to his desk and asked me to address my classmates. I was forced to read a passage aloud. This scenario made me nervous (P53, Male).

Learners appear to enjoy group activities in the classroom over being made to stand in front of the class alone.

\subsubsection{Instructor skills}

Instructor skills, which included pedagogical practices, were another source of both FLE and FLCA. Some participants expressed their satisfaction of the instructor's ability to create a pleasant learning atmosphere, which resulted in experiencing many enjoyable scenarios in the classroom. For example, Participant 7 enjoyed the instructor's work to engage students in the learning process: 
I enjoyed my teacher's way of teaching. She designs fun activities and uses music as a tool to energize students. I love the way she interacts with us (P7, female).

Students also seemed to experience enjoyable episodes when they received support and encouragement from their teacher:

It felt good when my teacher acknowledged my hard work. He thought I was one of his best students. (P4, male).

Other students mentioned particular teachers who bring joy to the classroom because of their willingness to assist students:

The presence of wonderful, caring professors such as MS Sonia makes us enjoy our English classes. I appreciate all the help and dedication she shows to students. She is very approachable. (P1, female).

The instructor attitude was a source of anxiety for some participants. Participant 60 remembers a painful episode that caused him frustration:

Each time I make a mistake the instructor gets upset. Students are supposed to make mistakes. This instructor was not supportive (P60, male).

Teachers who resort to intimidation techniques trigger anxiety among students as mentioned by Participant 3:

One of my professors started warning us that very few students would be able to pass the course and that no student would get an A. I understand that the professor wanted to push us to work harder but it created a very uncomfortable learning atmosphere (P3, female).

It is not surprising that teachers who build rapport with students and who show care and support manage to create a positive learning environment where learners enjoy their language classes. Conversely, instructors who use intimidation tactics as if they are in the military will most likely see their strategies backfire. This will result in students experiencing more negative feelings, including anxiety and loss of interest, rather than experiencing the joy of learning.

\subsubsection{Personal success/failure}

The extent to which students enjoy their course can be influenced by their perceptions of success and failure. Participant 55, for example, remembers feeling very happy when he managed to communicate in English:

Last semester I was full of joy when I was able to communicate perfectly with my instructor without a single problem. Reaching a certain level of proficiency is very rewarding (P55, male). 
However, Participant 71 experienced a sense of failure when struggling to keep up with the teacher along with the following emotion:

It was very frustrating when I fail to understand certain concepts. Sometimes I can't follow the instructor because of my lack of understanding (P71, male).

Students that perceive success are more likely to enjoy their course, whereas the enjoyment of those that experience failure is inhibited.

\subsubsection{Evaluation}

Many participants especially males, like Participant 24 cited teacher assessment as a source of enjoyment or anxiety:

When I was freshmen, my anxiety levels went up because of my low grades. It was struggle as I started to question my ability to pass my courses. I even considered changing my major. However, when my grades improved during the subsequent semesters I felt good. It was exciting to get high grades in translation courses, for example (P11, male).

Another participant had a similar experience:

The first year at university was quite tough. Fear of negative evaluation crippled my ability to do well in exams. Later, I as I worked harder. I was able to overcome my anxiety, and my grades improved (F15, female).

Grades seem to have an impact on academic motivation. Good grades enhanced enjoyment and self-confidence in one's ability to succeed among participants. In contrast, bad grades seem to have the potential to thwart basic psychological needs and academic motivation, and trigger anxiety.

\subsubsection{Other}

This category covers participants' statements that did not point out to a specific source of anxiety or enjoyment. For example, one participant stated that he had a good learning experience:

I enjoyed everything about my English classes" (P258, male). Another participant expressed her dislike of English classes: "I don't like English and I find classes boring" (P344, female).

There is a tendency among groups of participants when summarizing their experiences about whether they like their English classes or not: their experience of enjoyment or anxiety depends on how they feel overall about the course. 


\section{Discussion}

The first research question investigated levels of FLE and FLCA of Saudi EFL learners. The mean for FLE in the present study (3.61) is lower than the mean reported by the international sample of Dewaele \& MacIntyre (2014), which was 3.82 and the mean reported by Jiang \& Dewaele (2019), which was 3.94. The mean for FLCA (3.70) is much higher than the mean reported by Jiang \& Dewaele (2019) which was 3.14 and the mean reported in Dewaele \& MacIntyre's (2014) study, which was 2.75. This outcome corroborates the findings reported in previous studies, which state that Saudi EFL learners tend to experience higher levels of anxiety compared to students in other countries (e.g., Alrabai, 2015; Hamouda, 2012). Students' experience of high anxiety levels could be ascribed to the educational context in Saudi where students are not exposed enough to English, since instructors tend to use Arabic extensively in the classroom (Alrabai, 2016). EFL teachers' lack of qualifications (e.g., Al-Hazmi, 2003) could have contributed to the creation of a classroom environment that triggered anxiety among learners.

Our second research question addressed the relationship between FLE and FLCA. A negative correlation was found between students' FLE and FLCA, which means that participants who experience higher levels of FLE tend to have lower levels of FLCA. The results are in line with Dewaele \& MacIntyre's (2014) finding which reported a small effect size (Cohen, 1992), since FLE and FLCA shared $12.9 \%$ of their variance. In the current study, FLE and FLCA shared only $3.6 \%$ of their variance. It can be argued that enjoyment and anxiety are opposite ends of the spectrum but as MacIntyre \& Legatto (2011) observed, it may be possible to witness learners who are enjoying their English classes, but at the same time, are experiencing episodes of anxiety." (Dewaele \& MacIntyre, 2014).

The potential impact of gender on FLE and FLCA was addressed in our third research question. The results indicated no significant difference between levels of FLE among male $(M d n=35)$ and female learners $(M d n=36), U=22329, p \square .05)$. Similarly, there was no significant difference between levels of FLCA amongst male $(M d n=30)$ and female learners $(M d n=29), U=22329, p \square .05)$. The difference between female and male respondents was only significant for two items of FLE, with females feeling like they were worthy members of their English classes and that it is "cool" to know English. Similarly, the difference between male and female participants was only significant for two items of FLCA, with females showing more anxiety despite feeling well prepared for their English classes, and experiencing panic when they had to speak without preparation in the English class. The insignificant role of gender reported in the current study corroborates the results found by Jiang \& Dewaele (2019), but contradicts previous studies where female students reported both more FLE and 
FLCA than male students (Dewaele \& MacIntyre 2014; Dewaele et al. 2016). The lack of gender effect on FLCA revealed by the current study is an unexpected finding since previous research has shown that female Saudi students tend to experience higher levels of FLCA than male students (Bensalem, 2018, Bensalem, 2019). Some argue that this is because in Saudi Arabia cultural norms place expectations on women to be reserved and even may discourage women from engagement in academic activities (Song, 2018). As Dewaele (2018) argued, one possible explanation of the lack of gender effect on enjoyment and anxiety is that students who choose to participate in this survey are typically good learners who are pleased with their English classes, rather than weak students. The sample may have included students who rejected the crippling effects of social norms. Therefore, the effect of gender may have been neutralized because of the profile of the participants. In other words, if the participants had been mostly struggling students the outcomes may have been different.

The fourth research question focused on the effect of self-perceived proficiency in English and year of study on the participants' FLE and FLCA. Results showed that year of study was not a predictor of FLE and FLCA, which suggests the fact that participants experienced the same levels of enjoyment and anxiety regardless of their year of study. Conversely, self-perceived proficiency in English predicted both FLCA and FLE. This outcome echoes the findings in Dewaele \& Macintyre (2014) and Li et al. (2018). This suggests that learners who experience a high level of FLE and a low level of FLCA tend to have more confidence and more optimistic self-assessment of foreign language proficiency. This result is aligned with Horwitz et al.'s (1986) claim that there is a relationship between FLCA and self-perceptions in foreign language.

Finally, participants were asked to share their enjoyable and anxious episodes in the EFL class. Content analysis of the participants' responses generated four major themes that shed light on sources of enjoyment and anxiety: classroom activities, instructor skills, personal success/failure in the classroom, and assessment. Three of these themes were similar to those related to FLE reported by Dewaele \& MacIntyre (2014), namely classroom activities, instructor skills, and personal success/failure in the classroom. However, only one theme was similar to the ones found by Dewaele \& Alfawzan (2018), whose study was conducted in the Saudi context. One possible explanation is the profile of participants in Dewaele \& Alfawzan's (2018) study was different. They were mostly users of English who had already graduated. Students who are still involved in the learning process have different experiences and perceptions than those who have successfully completed their studies. One of the unique themes revealed by the current study is related to assessment. Fear of negative evaluation was widely discussed as a main source of anxiety for FL learners (e.g., Aida 1994; Horwitz \& Young, 1991; Sellers 2008; Zhang \& Zhong, 2012), but assessment as a source of enjoyment had not been discussed in previous research on FLE. It was interesting 
to read how the majority of participants cited fear of negative evaluation when they described anxious classroom experiences, while receiving positive evaluation as the most memorable, enjoyable experiences in EFL classes. This could be explained by cultural norms in Saudi Arabia. Getting bad grades can cause embarrassment and "loss of face". According to Saudi culture, "loss of face" may result in loss of honor and respect of others (Al-Saraj, 2014). Conversely, getting good grades will bring pride and respect, even to parents and the whole family. Furthermore, the opportunities that come with good grades include full scholarships and good jobs since some employers check transcripts before hiring potential candidates in Saudi Arabia.

\section{Conclusions}

The current study examined the construct of FLE and its relationship with FLCA among 487 EFL college level Saudi students. Participants reported similar FLE levels to previous studies, but FLCA levels were higher than those reported in recent research. Male and female students had the same levels of FLE and FLCA. Correlation analysis revealed a negative significant relationship between FLE and FLCA. However, in terms of individual items, female participants felt significantly stronger than their male peers that they were more worthy members of the English language class and agreed more strongly that it is "cool" to know English. Similarly, female students felt more anxious in the English class and experienced panic situations when they had to speak without preparation in the English class. The study confirmed the assumption that self-perceived proficiency in foreign language could be a predictor for FLE and FLCA, while of study had no effect on participants' FLE and FLCA. Qualitative material collected from participants revealed that classroom activities, instructor skills, personal success/failure in the classroom, and assessment were reported to be the main causes of anxiety and enjoyment for male and female participants. Further research could focus on the role of other variables that my combine with gender to influence FLCA and FLE (Dewaele et al., 2016), such as socio-economic status, proficiency in additional languages, and experience abroad. It would be interesting to examine whether the gender patterns in FLE and FLCA are similar for Saudi students enrolled in international schools to those enrolled in public schools.

A number of pedagogical implications can be drawn from this study. Participants cited teacher classroom practices as one of several sources of anxiety and enjoyment. Previous research has documented that learner attributes such as personality and personal experience could be sources of FLE and FLCA not related to the classroom. However, teachers could still play a major role in alleviating anxiety and boosting enjoyment among students. Teachers can turn the classroom into a safe learning environment by being friendly, supportive, humorous, and considerate. Consequently, 
learners will be able to experience higher levels of enjoyment (Dewaele \& Macintyre, 2014; Oxford, 2017). Dewaele et al., (2019a) pointed out to the crucial role by FLE in achieving a successful L2 classroom learning experience. Students with a positive attitude tend to be more involved in the learning process and make the best out of learning opportunities. Furthermore, teachers should carefully design activities that are enjoyable and involve all students regardless of their proficiency levels and interests. Such activities can certainly boost students' positive emotions and help them achieve better performance in the FL class (Dewaele \& Alfawzan, 2018).

Participants of the current study report fear of failure as a source of anxiety. In this regard, Oxford (2017) suggests teachers should take initiative to strengthen an anxious learner's ability by helping them focus and visualize a positive or interesting fact of the language activity or text, and removing any negative thoughts of failing or difficulty. Teachers should also aid them in releasing any emotional icebergs and grudges they may still hold.

The current study has limitations, which make the findings hard to generalize even though the sample size is relatively large. First, the participants were self-selected. As Dewaele (2018) argued, learners who choose to take the time to fill out a questionnaire are most likely those who are having a good learning experience, rather than learners who are not satisfied with their language performance. Another limitation is the data itself were collected mainly from two universities out of over 30 universities located in Saudi Arabia. Therefore, students from other universities with different academic setting, including teaching staff, may have different perceptions even though the cultural norms are applicable to all students. Thirdly, several learner variables were not accounted for, such as language proficiency, study abroad experience, or knowledge of a third knowledge. These variables, along with motivation, could have influenced the outcomes of the study.

\section{Acknowledgement}

The author wishes to acknowledge the approval and the support of this research study by the grant no. 7718-EAR-2018-3-9-F from the Deanship of Scientific Research at Northern Border University, Arar, K.S.A

\section{References}

Aida, Y. (1994). Examination of Horwitz, Horwitz, and Cope's construct of foreign language anxiety: The case of students of Japanese. The Modern Language Journal, 78(2), 155-168. 
Al-Hazmi, S. H. (2003). EFL teacher preparation programs in Saudi Arabia: Trends and challenges. TESOL Quarterly, 37(2), 341-344

Alrabai, F. (2015). The influence of teachers' anxiety-reducing strategies on learners' foreign language anxiety. Innovation in Language Learning and Teaching, 9(2), 163-190.

Alrabai, F. (2016). Factors underlying low achievement of Saudi EFL learners. International Journal of English Linguistics, 6(3), 21-37

Al-Saraj, T. M. (2014). Revisiting the Foreign Language Classroom Anxiety Scale (FLCAS): The Anxiety of Female English Language Learners in Saudi Arabia. L2 Journal, 6(1), 50-76.

Bensalem, E. (2018). Foreign Language Anxiety of EFL Students: Examining the effect of self-efficacy, self-perceived proficiency and sociobiographical variables. Arab World English Journal, 9(2), 38-55Bensalem, E. (2019). Multilingualism and Foreign Language Anxiety: the case of Saudi EFL Learners. Learning and Teaching in Higher Education: Gulf Perspectives, 15(2), 1-14.

Boudreau, C., MacIntyre, P. D., \& Dewaele, J.-M. (2018). Enjoyment and anxiety in second language communication: an idiodynamic approach. Studies in Second Language Learning and Teaching, 8, 149-170

Bown, J., \& White, C. J. (2010). Affect in a self-regulatory framework for language learning. System, 38(3), 432-443. Cohen, J. (1992). Statistical power analysis. Current Directions in Psychological Science, 1(3), 98-101. Oxford: Blackwell Publishing.

Cohen J. (1988). Statistical Power Analysis for the Behavioral Sciences. New York: Routledge Academic

Creswell, J. W., \& Plano Clark, V. L. (2011). Designing and Conducting Mixed Methods Research (2nd ed.). Los Angeles: Sage Publications Ltd.

Denies, K, Janssen, R (2016) Country and gender differences in the functioning of CEFR-based can-do statements as a tool for self-assessing English proficiency. Language Assessment Quarterly 13(3), 251-76.

De Smet, A., Mettewie, L., Galand, B., Hiligsmann, Ph., \& Van Mensel, L. (2018). Classroom anxiety and enjoyment in CLIL and non-CLIL: Does the target language matter? Second Language Learning and Teaching, 8(1), 47-72

Dewaele, J.-M. (2005). Investigating the psychological and the emotional dimensions in instructed language learning: Obstacles and possibilities. The Modern Language Journal, 89(3), 367-380.

Dewaele, J.-M. (2018). Online questionnaires. In A. Phakiti, P. De Costa, L. Plonsky \& S. Starfield (Eds.), The Palgrave Handbook of Applied Linguistics Research Methodology (pp. 269-286). Basingstoke: Palgrave Macmillan. 
Dewaele, J.-M. \& Alfawzan, M. (2018). Does the effect of enjoyment outweigh that of anxiety in foreign language performance? Studies in Second Language Learning and Teaching, 8, 21-45.

Dewaele, J.-M. \& Dewaele, L. (2017). The dynamic interactions in foreign language classroom anxiety and foreign language enjoyment of pupils aged 12 to 18 . A pseudolongitudinal investigation. Journal of the European Second Language Association, 1, 12-22.

Dewaele, J.-M., \& MacIntyre, P.D. (2014). The two faces of Janus? Anxiety and enjoyment in the foreign language classroom. Studies in Second Language Learning and Teaching, 4, 237-274

Dewaele, J.-M., \& MacIntyre, P.D. (2016). Foreign language enjoyment and foreign language classroom anxiety: The right and left feet of the language learner? In P. D. MacIntyre, T. Gregersen, \& S. Mercer (Eds.), Positive psychology in SLA (pp. 215-236). Multilingual Matters.

Dewaele, J.-M., \& MacIntyre, P.D. (2019). The predictive power of multicultural personality traits, learner and teacher variables on foreign language enjoyment and anxiety. In M. Sato \& S. Loewen (Eds.), Evidence-based second language pedagogy: A collection of Instructed Second Language Acquisition Studies. London: Routledge.

Dewaele, J.-M., MacIntyre, P. D., Boudreau, C., \& Dewaele, L. (2016). Do girls have all the fun? Anxiety and enjoyment in the foreign language classroom. Theory and Practice of Second Language Acquisition, 2(1), 41-63.

Dewaele, J.-M., Franco Magdalena, A., \& Saito, K. (2019a). The effect of perception of teacher characteristics on Spanish EFL learners' anxiety and enjoyment. Modern Language Journal, 103, 412-427.

Dewaele, J.-M., Özdemir, C., Karci, D., Uysal, S., Özdemir, E. D., \& Balta, N. (2019b). How distinctive is the foreign language enjoyment and foreign language classroom anxiety of Kazakh learners of Turkish? Applied Linguistics Review, 1, 1-23.

Dewaele, J.-M., Witney, J., Saito, K., and Dewaele, L. (2018). Foreign language enjoyment and anxiety in the FL classroom: the effect of teacher and learner variables. Language Teaching Research. 22, 676-697.

Elahi Shirvan, M. \& T. Taherian. (2018). Longitudinal examination of university students' foreign language enjoyment and foreign language classroom anxiety in the course of General English: Latent growth curve modelling. International Journal of Bilingual Education and Bilingualism, 30, 23-41.

Fredrickson, B. L. (2001). The role of positive emotions in positive psychology: The broaden-and-build theory of positive emotion. American Psychologist, 56, 218-226. 
Hamouda, A. (2012). An exploration of causes of Saudi students' reluctance to participate in the English language classroom. International Journal of English Language Education, 1(1), 1-34.

Horwitz, E., Horwitz, M., \& Cope, J. (1986). Foreign language classroom anxiety. The Modern Language Journal, 70, 125-132.

Horwitz, E. K. \& Young, D.J. (Eds) (1991). Language anxiety: From theory and research to classroom implications. Englewood Cliffs, NJ: Prentice Hall.

Horwitz, E. K. (2001). Language anxiety and achievement. Annual Review of Applied Linguistics, 21(1), 112-126.

Jiang, Y., and Dewaele, J. M. (2019). How unique is the foreign language classroom enjoyment and anxiety of Chinese EFL learners? System, 82, 13-25.

Jin, Y. X., \& Dewaele, J.-M. (2018). The effect of positive orientation and perceived social support on foreign language classroom anxiety. System, 74, 149-157.

Khajavy, G. H., MacIntyre, P. D. \& E. Barabadi (2018). Role of the emotions and classroom environment in willingness to communicate: Applying doubly latent multilevel analysis in second language acquisition research. Studies in Second Language Acquisition, 40, 605-624.

Li, C., Jiang, G., \& Dewaele, J.-M. (2018). Understanding Chinese high school students' foreign language enjoyment: Validation of the Chinese version of the Foreign Language Enjoyment Scale. System 76, 183-196.

MacIntyre, P. D. (2017). An overview of language anxiety research and trends in its development. In C. Gkonou, M. Daubney, \& J.-M. Dewaele (Eds.), New insights into language anxiety: Theory, research and educational implications (pp. 11-30). Bristol: Multilingual Matters.

MacIntyre, P.D., \& Gregersen, T. (2012). Emotions that facilitate language learning: The positive broadening power of the imagination. Studies in Second Language Learning and Teaching, 2, 193-213.

MacIntyre, P. D., \& Legatto, J. J. (2011). A dynamic system approach to willingness to communicate: Developing an idiodynamic method to capture rapidly changing affect. Applied Linguistics, 32, 149-171.

MacIntyre, P.D., \& Mercer, S. (2014). Introducing positive psychology to SLA. Studies in Second Language Learning and Teaching, 4, 153-172

Mierzwa, E. (2019a). Foreign Language learning and teaching Enjoyment: Teachers' Perspectives. Journal of Education Culture and Society, 2(10), 170-188. 
Mierzwa, E. (2019b). Foreign language enjoyment among English Philology students: what do students enjoy while learning English as a FL? Theory and Practice in English Studies, 8(1), 7-21

Oxford, R. (2017). Anxious language learners can change their minds: Ideas and strategies from traditional psychology and positive psychology. In C. Gkonou, M. Daubney, \& J.-M. Dewaele (Eds.), New insights into language anxiety: Theory, research and educational implications (pp. 179-199). Multilingual Matters.

Park, G. P., \& French, B. F. (2013). Gender differences in the foreign language classroom anxiety scale. System, 41, 462-471.

Pavelescu, L. M. \& PetriП, B. (2018). Love and enjoyment in context: Four case studies of adolescent EFL learners. Studies in Second Language Learning and Teaching, 8, 73-101.

Piniel, K. \& Albert, A. (2018). Advanced learners' foreign language-related emotions across the four skills. Studies in Second Language Learning and Teaching, 8, $127-147$.

Santos, A., Cenoz, J., \& Gorter, D. (2017). Communicative anxiety in English as a third language. International Journal of Bilingualism and Bilingual Education, 14(1), 23-37.

Sellers, V. (2008). Anxiety and reading comprehension in Spanish as a foreign language. Foreign Language Annals, 33, 512-521.

Shi, L. (2008). The successors to Confucianism or a new generation? A questionnaire study on Chinese students' culture of learning. Language, Culture and Curriculum, 19, 122-147.

Song, J. (2018). "She Needs to Be Shy!": Gender, culture, and nonparticipation among पSaudi Arabian female students. TESOL Quarterly, 53(2), 405-429.

Swain M. (2013). The inseparability of cognition and emotion in second language learning. Language Teaching, 46, 195-207.

Thompson, A. S., \& Lee, J. (2013). Anxiety and EFL: Does Multilingualism Matter? International Journal of Bilingual Education and Bilingualism, 16, 730-749.

Zhang, R., \& Zhong, J. (2012). The hindrance of doubt: causes of language anxiety. International Journal of English Linguistics, 2(3), 27-33. 


\section{Appendix: FLE and FLCA Questionnaire}

\section{Background Information}

1. Gender:

2. Age:

3. Year of study:

4. Have you visited an English speaking country?

Yes.

No.

5. Have participated in as study abroad program in an English speaking country such as England or the US?

Yes.

No.

6. Self-perceived proficiency in English:

On a scale from zero to ten, please select your level of proficiency in speaking English

$\begin{array}{llllllllll}1 & 2 & 3 & 4 & 5 & 6 & 7 & 8 & 9 & 10\end{array}$

On a scale from zero to ten, please select your level of proficiency in listening in English

$\begin{array}{llllllllll}1 & 2 & 3 & 4 & 5 & 6 & 7 & 8 & 9 & 10\end{array}$

On a scale from zero to ten, please select your level of proficiency in reading in English

$\begin{array}{llllllllll}1 & 2 & 3 & 4 & 5 & 6 & 7 & 8 & 9 & 10\end{array}$

On a scale from zero to ten, please select your level of proficiency in writing in English

$\begin{array}{llllllllll}1 & 2 & 3 & 4 & 5 & 6 & 7 & 8 & 9 & 10\end{array}$




\section{To what extent do you agree with the following statements? Strongly disagree/ Disagree/Undecided/ Agree /Strongly agree}

\section{A. Foreign Language Enjoyment Scale}

1. I don't get bored

2. I enjoy it

3. I'm a worthy member of the Foreign language class

4. In class, I feel proud of my accomplishments

5. It's a positive environment

6. It's cool to know a Foreign language

7. it's fun

8. The peers are nice

9. There is a good atmosphere

10. We laugh a lot

\section{B. Foreign Language Classroom Anxiety}

1. Even if I am well prepared for Foreign language class, I feel anxious about it

2. I always feel that the other students speak the Foreign language better than I do

3. I can feel my heart pounding when I'm going to be called on in Foreign language class

4. I don't worry about making mistakes in Foreign language class (reverse)

5. I feel confident when I speak in Foreign language class (reverse)

6. I get nervous and confused when I am speaking in my Foreign language class 
7. I start to panic when I have to speak without preparation in Foreign language class

8. It embarrasses me to volunteer answers in my Foreign language class

\section{Open questions}

a. Describe one specific event or episode in your Foreign language class that you really enjoyed, and describe your feeling in as much detail as you can.

b. Describe one specific event or episode in your Foreign language class that made you really anxious, and describe your feeling in as much detail as you can. 